\title{
The role of multimodality imaging in clinical decision-making of the heart team in complex aortic root reconstruction due to endocarditis
}

\section{DDubravka Šušnjar1*, DSandra Jakšić Jurinjak', \\ DBoris Starčević1,2, (D)Josip Varvodić', (iD)Davor Barić', DDaniel Unić1, (D)Robert Blažeković', (i) Igor Rudež ${ }^{1,2}$}

'University Hospital Dubrava Zagreb, Croatia

${ }^{2}$ University of Zagreb School of Medicine, Zagreb, Croatia
KEYWORDS: aortic root reconstruction, aortic valve insufficiency, endocarditis. CITATION: Cardiol Croat. 2019;14(3-4):78-9. | https://doi.org/10.15836/ccar2019.78

*ADDRESS FOR CORRESPONDENCE: Dubravka Šušnjar, Klinička bolnica Dubrava, Av. Gojka Šuška 6, HR-10000, Zagreb, Croatia. / Phone: +385-99-290-4019 / E-mail: dubravka.susnjar@gmail.com

ORCID:Dubravka Šušnjar, https://orcid.org/0000-0002-9644-9739• Sandra Jakšić Jurinjak, https://orcid.org/0000-0002-7349-6137 Boris Starčević, https://orcid.org/0000-0002-3090-2772 • Josip Varvodić, https://orcid.org/0000-0001-6602-699X Davor Barić, https://orcid.org/0000-0001-5955-0275 • Daniel Unić, https://orcid.org/0000-0003-2740-4067 Robert Blažeković, https://orcid.org/0000-0001-7125-361X•Igor Rudež, https://orcid.org/0000-0002-7735-6721

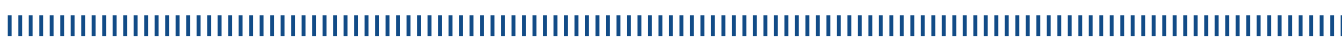

Case report: 29-year-old male underwent aortic root reconstruction with root remodeling technique and external ring annuloplasty (Corneo Extra Aortic Ring A 29, Gelweave graft $30 \mathrm{~mm}$ ) in 2015 due to bicuspid aortic valve with significant aortic regurgitation and aortic root dilatation. In 2017 due to pseudoaneurysm of aortic root and severe aortic regurgitation, the patient was reoperated and mechanical aortic valve was implanted (Carbomedics Mechanical A 25) with patch plastic of the pseudoaneurysm. A year later he was admitted again, now due to fever and high inflammatory markers. Multimodality imaging, transthoracic echocardiography, transesophageal echocardiography, MSCT aortography and abdominal CT described aortic /perivalvular root abscess with significant paravalvular leak in terms of hemodynamically significant regurgitation with high flow velocity over the mechanical valve, peak velocity $>4 \mathrm{~m} / \mathrm{s}$. TEE (2D+3D) showed the septate hyperechogenic formation with hypoechogenic cavities which seemed to touch a part of trigonum, approximately $15 \mathrm{~mm}$ thick, extending from annulus ascending to the entire visible part of the aortic root, ascending more than $4 \mathrm{~cm}$. It appeared to affect $>50 \%$ of the annulus, with visible paraannular leak and massive aortic regurgitation. Previously implanted patch plastic on aortic root was hypermobile depending on heart cycle. Left ventricle showed normal contractility. MSCT of thorax and aortography confirmed the finding (Figure 1). The patient
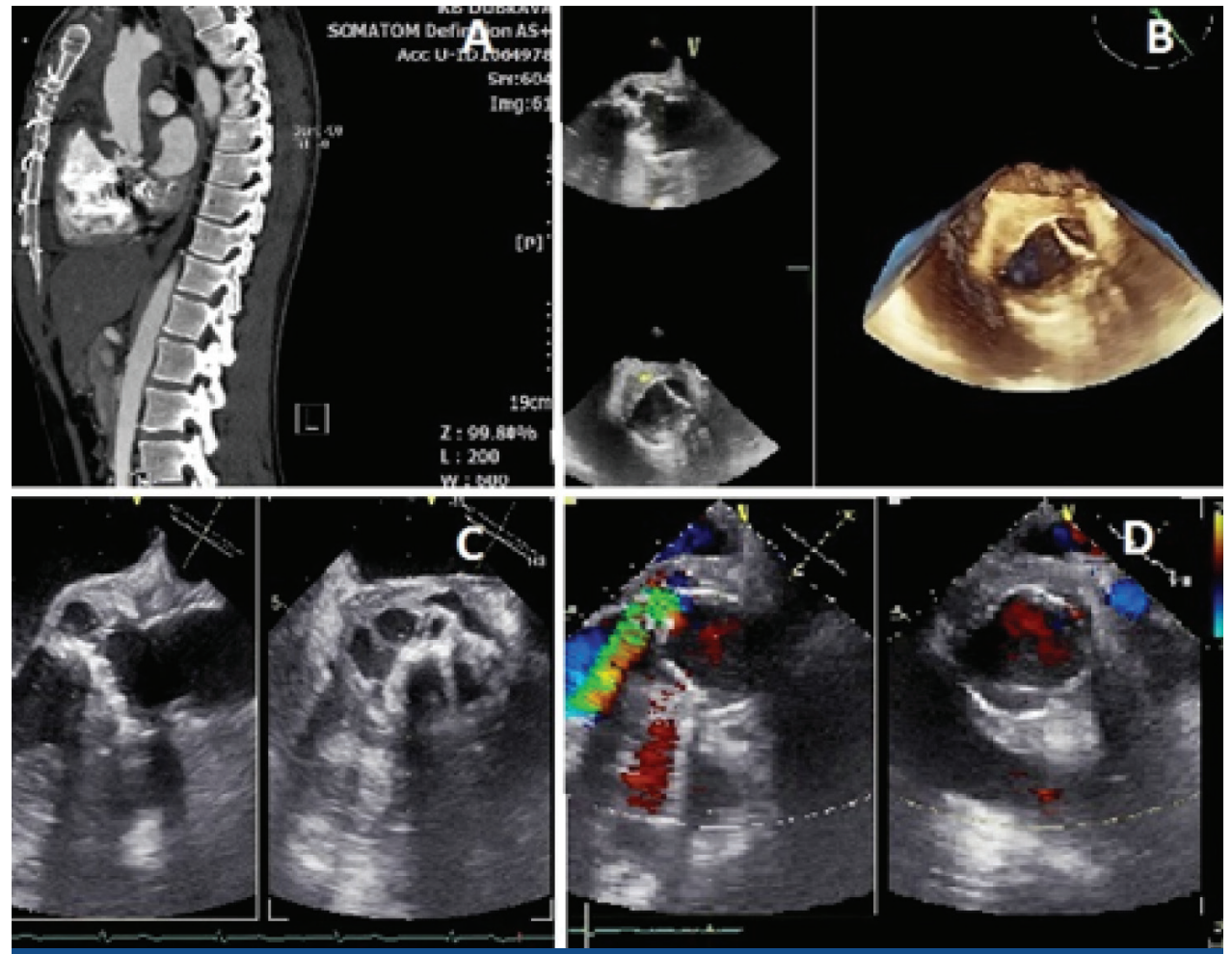

FIGURE 1. A MSCT aortography showing complex aortic root abscess, B 3D TEE of aortic root showing patch plastic protruding into aortic lumina, C, D multiplane transoesophageal echocardiography showing paraannuluar aortic abscess with paraannular regurgitant jet. $\square$ Cardiologia Croatica 2019:14(3-4):78
10. hrvatski dvogodišnji ehokardiografski kongres s međunarodnim sudjelovanjem $10^{\text {th }}$ Croatian Biennial Echocardiography Congress with International Participation Poreč, 16. do 18. 5. 2019. 
was diagnosed with endocarditis of the mechanical aortic valve and aortic root abscess, thus the antimicrobial therapy was started. Patient had to undergo urgent surgical reoperation. Aortic root replacement with coronary artery reimplantation was performed (sec Bentall, BioIntegral Surgical A 23). There were no signs of paravalvular leak on the control MSCT aortography, with proper flow through graft, coronary artery and supra-aortal branches. Control echocardiography showed a good function of the mechanical valve. Patient recovered successfully and was sent home after antimicrobial therapy protocol was finished.

Conclusion: Cooperation of the heart team (cardiologist, heart surgeon, radiologist) and multimodality imaging is a paramount for accurate diagnosis and management of patients with complex aortic pathology ${ }^{1,2}$

2. Lansac E, Di Centa I, Raoux F, Bulman-Fleming N, Ranga A, Abed A, et al. An expansible aortic ring for a physiological approach to conservative aortic valve surgery. J Thorac Cardiovasc Surg. 2009 Sep;138(3):718-24. https://doi.org/10.1016/j.jtcvs.2009.05.024 